\title{
Modeling parameters for predicting the postbuckling shear strength of steel plate girders
}

\author{
Jonathan D. Glassman ${ }^{1}$, Maria E. Moreyra Garlock ${ }^{2}$, Esam M. Aziz ${ }^{3,4}$, Venkatesh K. Kodur ${ }^{5}$ \\ ${ }^{1}$ Associate, Exponent Failure Analysis Associates, jglassman@exponent.com \\ ${ }^{2}$ Associate Professor, Department of Civil and Environmental Engineering, Princeton University, \\ mgarlock@princeton.edu
}

${ }^{3}$ Research associate, Department of Civil and Environmental Engineering, Michigan State University, azizesam@egr.msu.edu

${ }^{4}$ College of Engineering, University of Sulaimani, Sulaymaniyah, Iraq

${ }^{5}$ Professor, Department of Civil and Environmental Engineering, Michigan State University, kodur@egr.msu.edu

\begin{abstract}
:
Bridge fires are becoming an increasing concern, and for steel plate girder bridges in particular, web shear buckling is one of the failure mechanisms that can make it necessary to replace the girder after the fire is extinguished. The objective of this study is to evaluate the web shear buckling response of two experimental plate girder specimens subject to fire conditions, and also to determine how complex computational models must be to accurately characterize the web shear buckling response of steel plate girders subjected to fire. Three parameters are evaluated: boundary conditions representing the flange, representation of thermal gradients, and composite action with the slab. To meet this objective, finite element models with varying parameters are compared to each other and to experimental results. Results show that the presence of a composite slab significantly increases the shear capacity of the plate girder. The presence of thermal gradients makes finite element modeling of the flange more sensitive to the results compared to a uniform temperature distribution. Modeling the girder with a uniform
\end{abstract}


temperature equal to the temperature of the web leads to similar results as modeling with thermal gradients.

Keywords: postbuckling, shear strength, finite element, steel plate girder, thermal gradient, bridge fire

\subsection{Introduction}

Fires pose a significant risk to highway infrastructure, particularly steel plate girder bridges [1]. The lack of fire protection (active or passive) means that steel members may be directly exposed to elevated temperatures in the event of a fire occurring beneath or adjacent to a bridge. Additionally, since these steel plate girder bridges typically have high web slenderness ratios, they are prone to web shear buckling failures at elevated temperatures [2, 3].

Several notable fires have occurred throughout the United States that have caused steel girder bridges to collapse or be severely damaged [1]. The collapse of two spans of the I-80 east to I580 east flyover within the MacArthur Maze freeway complex in Oakland, California due to a tanker truck fire underscores the severity of these fire scenarios. The aftermath of this collapse that occurred on April 29, 2007 is shown in Figure 1(a). Replacing the bridge cost $\$ 9$ million, while the economic impacts to the San Francisco Bay area were estimated to be $\$ 6$ million per day of the bridge closure (26 days total) [1]. Figure 1(b) shows a tanker fire within the I-

81/Route 322 interchange in Harrisburg, Pennsylvania on May 9, 2013. While the steel bridge did not collapse, extensive damage prompted its demolition. Figure 1(c) shows extensive deformations in bridge steel plate girders due to a tanker truck fire at the I-65/I-59/I-20 interchange in Birmingham, Alabama on January $5^{\text {th }}, 2002$. Similar to the tanker truck fire shown in Figure 1(b), the bridge did not collapse but the damage was extensive and the structure was 
demolished and rebuilt. Web shear buckling was observed in the bridges shown in Figures 1(b) and 1(c), which motivated studies to explore how this failure mechanism contributes to the fire performance of steel plate girder bridges $[2,4]$.

Most finite element analyses and experiments that have studied web shear buckling at elevated temperatures were conducted at steady state, uniform temperatures $[2,5,6,7]$. These studies have been important steps in understanding how postbuckling shear strength develops at higher temperatures, but in real fire scenarios thermal gradients would be expected to develop in the steel plate girders due to uneven heating of the structure, environmental conditions such as wind, and the varying nature of the fire itself [8].

A recent study by Peris-Sayol et al. $[9,10]$ numerically re-created a complete bridge fire scenario from the development of the fire loading to its effects on the bridge itself. Computational fluid dynamics (CFD) models numerically characterized the fire loading from a tanker truck crashing adjacent to a steel plate girder highway bridge. Using the results from their CFD model, the authors were then able to use finite element modeling to characterize the structural fire performance of the non-composite bridge subjected to the fire scenario.

Michigan State University in partnership with Princeton University conducted experiments on three different composite steel girders subjected to a design fire loading. The girders that were tested experienced thermal gradients since the experiments were done in transient temperature conditions (i.e., a time-temperature curve was used). The objective of these experiments was to study the flexural and shear capacity of steel plate girders subjected to fire. Relevant details of this experiment are discussed in the next section and additional details may also be found in [4]. The work presented in this current paper builds on this experimental work by focusing on web shear buckling. 
The objective of this study is to (1) evaluate the web shear buckling response of two experimental specimens under fire conditions and (2) determine how complex computational models must be to accurately characterize the web shear buckling response of steel plate girders subjected to fire. Three parameters are evaluated: boundary conditions representing the flange, representation of thermal gradients, and composite action with the slab. To meet this objective, finite element models with varying parameters are compared to each other and to experimental results. This work is novel and significant since, as discussed previously, bridge fires are becoming an increasing concern, especially for steel plate girder bridges, where web shear buckling can lead to significant damage and lead to demolition of the bridge. Further, this is the first study of shear buckling of web plates under thermal gradients and composite action with a slab.

\subsection{Experiments}

The authors conducted experiments on three steel girders at Michigan State University [4]. This section of the paper expands upon the work discussed in [4] by presenting a specific and deeper analysis of the web shear buckling response of two girders that were tested. The experimental setup and methodology are discussed; of the three girders tested, two of them were observed to have experienced web shear buckling as a result of the combined mechanical and thermal applied loading. The third girder experienced a flexural failure due to the combined mechanical and thermal loading and, since web shear buckling was not observed for this girder, it is not the focus of this particular discussion. A full treatment of the flexural response of steel girders to combined mechanical and thermal loading can be found in $[4,11]$.

\subsection{Setup}


Three steel girders were tested in three separate tests at Michigan State University, labeled G1, G2, and G3. These girders were tested to failure under combined mechanical and high temperature loadings. Girder G1 was a hot rolled W24x62 section, while girders G2 and G3 were built-up plate girders designed according to the 2012 AASHTO LRFD Bridge Design Specifications [12]. All three specimens were fabricated with A572 Gr 50 steel, a high strength, low-alloy steel that is common for highway bridge construction. The following discussion will focus specifically on girders G2 and G3 since their slenderness ratio, measured as the depth of the web between flanges $(D)$ divided by the web thickness $\left(t_{w}\right)$, equals 122 , thus making these girders susceptible to web shear buckling.

Table 1 lists the physical dimensions and loading parameters of girders G2 and G3. Both girders were constructed with a $0.140 \mathrm{~m}$ thick concrete slab, a $0.831 \mathrm{~m}$ effective width, and were designed to achieve full composite action. This concrete slab was an integral part of the furnace setup because it also served as the top lid of the furnace, sealing the chamber so that the furnace temperature could be regulated. In addition, it allowed the test girders to be exposed to a threesided fire situation, which resembles an actual bridge fire scenario. The effective width was equal to twice the distance between the girder centerline and the furnace wall. From Table 1, the applied load value ( $\left.V^{E x p}\right)$, which was held constant, was selected such that both girders G2 and G3 had the same $V^{E x p} / V_{u}^{\text {Design }}$ value, where $V_{u}^{\text {Design }}$ equals the shear capacity of the specimen at ambient temperature.

Figure 2 shows the placement of girder G3 in the furnace before the combined mechanical and fire loading test started. The actuator shown in Figure 2 was positioned at mid-span for both girders G2 and G3. Additional details of this experimental setup can be found in [4]. 
The test specimens were first mechanically loaded by gradually increasing the hydraulic pressure in the actuator. Once the target load, $V^{E x p}$, was reached, a 30 minute hold time was maintained to allow the actuator loading to stabilize. Following this 30 minute hold, the fire loading following the ASTM E119 temperature versus temperature fire curve was applied while $V^{E x p}$ was maintained constant. The girders were considered to have failed when either the midspan vertical deflection was recorded to have exceeded $L / 30$ ( $L$ equals span length) or the girders could no longer sustain the applied load, $V^{\text {Exp }}$.

Girder G3 failed due to web shear buckling under the combined $V^{\text {Exp }}$ load and ASTM E119 time-temperature fire curve, while girder G2 failed in a combined web shear buckling and flexural mode [4]. Figure 3 shows two images of girder G3 where the web shear buckling mechanism is visible. Figure 3(a) is a photo taken through one of the portholes of the furnace that shows the formation of a diagonal tension field (visible as the region of out-of-plane deformations along the diagonal) during the fire. Figure 3(b) is a close-up image of these out-ofplane deformations in girder G3 after it has cooled and was removed from the furnace.

\subsection{Web shear buckling results}

Figure 4 shows representative cross-sectional and isometric views of girders G2 and G3.

Thermocouple locations for the top flange (Ttf1, Ttf2), bottom flange (Tbf1, Tbf2), and through the depth of the web (Tw1/4, Tw1/2, and Tw3/4) and stiffener (Tstf1/4, Tstf1/2, and Tstf3/4) are shown in Figure 4(a). Figure 4(b) shows how the cross-sectional temperatures were distributed

throughout the girder based on the thermocouple data. The sections labeled 1, 2, 3, 4, and 5 correspond with thermocouple data recorded from (1) the average of Tbf1 and Tbf2, (2) Tw1/4, (3) Tw1/2, (4) Tw3/4, and (5) the average of Ttf1 and Ttf2, respectively. 
Figure 5 plots temperature versus time data collected from the thermocouples shown in Figure 4 for girders G2 and G3, as well as the furnace temperature and the ASTM E119 fire curve to show how closely the furnace temperature matched the design fire curve. Figures 5(a) and (b) show a slight thermal gradient through the web of no more than $52^{\circ} \mathrm{C}$. It is also seen that the bottom flange temperature is similar to the web. However, a significant difference in temperature is observed between the top flange and the rest of the girder section.

Figure 6 plots the out-of-plane displacements of the web measured at the approximate center of the web panel adjacent to the mid-span for girders G1, G2, and G3. Since girder G1 failed due to flexure and did not experience web shear buckling, it has no measured out-of-plane web displacement. Girders G2 and G3 failed by reaching the limit of L/30 at 35 and 38 minutes, respectively, as marked in Figure 6.

Girder G2 experienced elastic buckling at approximately $t=27$ minutes, labeled in Figure 6 as the first point where out-of-plane web displacements were first measured. The point of failure (reaching $L / 30$ ) happened at 35 minutes, right before the actuator ran out of stroke at 36 minutes, which closely matches the largest out-of-plane displacement measured in the web plate. Girder G3 experienced elastic shear buckling at $\mathrm{t}=19$ minutes but did not fail until $\mathrm{t}=38$ minutes. Two minutes later the actuator ran out of stroke, and, like Girder G2, this time closely matches the maximum out-of-plane web displacement. Since this test held the gravity load constant and failure was measured by a deflection limit, and since the actuator ran out of stroke, evaluating a precise time at which ultimate postbuckling occurred is not possible. It is known that the capacity is at minimum equal to that achieved at the failure point of $L / 30$; therefore, it will be conservatively assumed that this time marks the point when the ultimate postbuckling shear capacity was reached. 
From Figure 6, it is seen that girder G3 had more time to develop its postbuckling shear strength than girder G2. The time difference between elastic and ultimate shear buckling was 8 minutes for girder G2 and 19 minutes for girder G3. The major difference between girders G2 and G3 was their $a / D$ values ( 1.0 for girder G2 and 1.5 for girder G3). Based on experimental observations, girder G3 failed due to web shear buckling while girder G2 failed due to a combination of flexure and web shear buckling.

Table 2 compares the temperatures in the top flange, quarter and half points through the depth of the web, and bottom flange measured when girders G2 and G3 reached both their elastic and ultimate postbuckling shear strengths. The results in this table show that the postbuckling shear strength for girders G2 and G3 developed over a time period in which the temperature of the girder section was changing. Based on Table 2, temperature differences $(\Delta \mathrm{T})$ ranging from $49^{\circ} \mathrm{C}$ to $231^{\circ} \mathrm{C}$ were observed over the time period when girders G2 and G3 were developing their respective postbuckling shear strength. Girder G2 reached elastic critical buckling at higher temperatures than Girder G3 because its smaller $a / D$ value corresponded with a larger buckling coefficient $(k)$ and, therefore, a larger critical buckling load. This result is due to larger $a / D$ ratios resulting in lower buckling coefficients $(k)$ and thus lower critical buckling loads. Ultimate shear buckling was reached at approximately the same temperature for girder G2 and girder G3. Since both girders have the same load ratio (i.e., applied load to design capacity load, which is based on ultimate shear buckling capacity), the same reduction in mechanical material properties is needed (which is a function of temperature) to achieve the load capacity.

\subsection{Finite Element Models}

In previous studies by the authors [4], finite element models were developed to show that they are "capable of predicting the fire response of steel bridge girders, time to failure, and failure 
pattern." In contrast, the current study uses finite element with the objective of determining which modeling parameters are sensitive to predicting the web shear postbuckling capacity of a steel plate girder. Such a sensitivity analysis answers the question of how complex a computational model needs to be while maintaining appropriate accuracy. To this end, three modeling parameters were studied:

1. Thermal gradients: the thermal gradients in the cross section were simplified, where two variations of uniform temperature through the depth and two variations of discretized thermal gradients were analyzed.

2. Flange representation: The flanges were either modeled as a simply supported (labeled $S S$ ) or they were explicitly modeled (labeled Flange).

3. Composite slab: The effect that a composite slab has on the shear capacity of the section is evaluated by comparing one model with a composite slab and one without.

The details of these parameters and the finite element models to develop this study are given in the subsections to follow. The results, and comparison to the experiments discussed previously, are given in the next section.

\subsection{Material model}

Steel coupons were taken from girders G2 and G3 for testing material properties at ambient temperature. These properties were reported in [4] and summarized in Table 3. Average values of the three measurements reported in Table 3 were used to develop the high temperature properties $\left(20^{\circ} \mathrm{C}\right.$ to $\left.1200^{\circ} \mathrm{C}\right)$ based on the Eurocode material model [13]. The $\sigma_{u}$ value in Table 3 was used as the $\sigma_{y}$ at $2 \%$ value in the Eurocode high temperature material model; using this 
model allowed for the high temperature material properties to be determined as a temperaturedependent reduction of the ambient temperature material properties.

\subsection{Modeling the Flange}

Figure 7 shows the two sets of finite element models that were used to represent the flange. These two sets, labeled SS and Flange, refer to finite element models where the flanges were replaced with simple supports or the flanges were explicitly modeled, respectively. Table 4 lists the boundary conditions assumed for the both the SS and Flange sets of finite element models (referred to in this paper as G2 SS, G2 Flange, G3 SS, and G3 Flange), where an "x" indicates a restrained degree of freedom. $\mathrm{U}_{\mathrm{X}}, \mathrm{U}_{\mathrm{Y}}$, and $\mathrm{U}_{\mathrm{Z}}$ refer to translational degrees of freedom in the $\mathrm{x}-$, y-, and z- axes, while $\mathrm{UR}_{\mathrm{X}}, \mathrm{UR}_{\mathrm{Y}}$, and $\mathrm{UR}_{\mathrm{Z}}$ refer to rotational degrees of freedom about the $\mathrm{x}-, \mathrm{y}-$, and z-axes. Transverse stiffeners are idealized as providing simple support to the web plate [14].

\subsection{Mesh convergence study}

A mesh convergence study was conducted using an eigenvalue extraction analysis at $20^{\circ} \mathrm{C}$ with the finite element software Abaqus. This is an elastic analysis that outputs a series of eigenvalues associated with particular eigenmodes (buckling mode shapes). Typically, the lowest positive eigenvalue is multiplied by the preload to obtain the elastic shear buckling load, $V_{c r}$. A linear superposition of multiple eigenmodes may be necessary if closely-spaced eigenvalues are observed, but this was not the case for the models studies. S4 (doubly curved, general-purpose, finite membrane strains) shell elements were selected for the mesh [15].

The $V_{c r}$ value obtained from the finite element eigenvalue extraction analysis $\left(V_{c r}{ }^{F E}\right)$ was compared with the value calculated using the classical equation [16]: 


$$
V_{c r}=\frac{k \pi^{2} E D t_{w}}{12\left(1-v^{2}\right)\left(D / t_{w}\right)^{2}}
$$

where $v$ is Poisson's ratio and $k$ is the elastic shear buckling coefficient, which depends on $a / D$ and the boundary conditions assumed for the flanges. For web plates that are simply supported on all four edges (simple supports assumed for the transverse stiffeners and flanges), $k=k_{S S}$ can be calculated as $[16,17]$ :

$$
\begin{aligned}
& k_{s s}=4.00+\frac{5.34}{(a / D)^{2}} \text { for } a / D<1 \\
& k_{s s}=5.34+\frac{4.00}{(a / D)^{2}} \text { for } a / D \geq 1
\end{aligned}
$$

When the flanges are explicitly considered, the $k$ value can be calculated as an interpolation between the case when the flanges are assumed to be simply supported or fixed. When the flanges are considered fixed $[14,16,18], k=k_{s f}$ can be calculated as:

$$
\begin{gathered}
k_{s f}=\frac{5.34}{(a / D)^{2}}+\frac{2.31}{(a / D)^{-3}}-3.44+8.39(a / D) \text { for } a / D<1 \\
k_{s f}=8.98+\frac{5.61}{(a / D)^{2}}-\frac{1.99}{(a / D)^{3}} \text { for } a / D \geq 1
\end{gathered}
$$

The actual $k$ value can then be calculated as $[18,14]$ :

$$
\begin{gathered}
k=k_{s S}+\frac{4}{5}\left(k_{s f}-k_{s S}\right)\left[1-\frac{2}{3}\left(2-\frac{t_{f}}{t_{w}}\right)\right] \text { for } 1 / 2 \leq t_{f} / t_{w}<2 \\
k=k_{s S}+\frac{4}{5}\left(k_{s f}-k_{s S}\right) \text { for } t_{f} / t_{w} \geq 2
\end{gathered}
$$


Various mesh densities were studied and the meshes selected had percent errors of $0.81 \%$, $1.28 \%, 0.88 \%$, and $1.83 \%$ for the G2 SS, G2 Flange, G3 SS, and G3 Flange models, respectively. Percent errors were calculated by taking the difference of $V_{c r}$ based on finite element from that based on Eqn. (1) and dividing by $V_{c r}$ based on Eqn. (1).

\subsection{Modeling the composite slab}

The models of Figure 7 and discussed thus far do not consider a slab. In previous experiments by the authors [4], however, a composite slab was present. The Flange finite element models presented in Figure 7 were thus modified to include the concrete slab, shown in Figures 8(a) and (b) for girders G2 and G3, respectively. Figure 8(c) shows a cross-sectional view of girders G2 and G3 with the slab dimensions labeled, including an effective slab width of $0.831 \mathrm{~m} \mathrm{[4].}$ Composite action was modeled by enforcing a 'tie constraint' [15] between the top surface of the top flange and the bottom surface of the concrete slab. The boundary conditions presented in Table 4 were employed for the steel section, while the two surfaces in Figure 8 labeled 'BCSlab' were assigned the same boundary conditions as side (4) in Table 4. Since the FE models discussed in this paper focus on a section of a composite steel plate girder between two

transverse stiffeners, the boundary conditions for side (4) represent continuity of the slab beyond the section studied.

Table 5 lists the concrete material properties that were experimentally determined and used for the slab [4], where the values for $f_{c}, f_{t}$, and $f_{c r}$ refer to the compressive strength, indirect tensile strength, and flexural strength at the recorded ages and the measurement taken at 210 days corresponds with the start of experimental testing. Poisson's ratio was taken as 0.2 , while Young's modulus at ambient temperature was calculated from the physical tests to be $3.8 \mathrm{e}+10$ 
$\mathrm{N} / \mathrm{m}^{2}$. The concrete slab was meshed with C3D8R (8-node linear brick, reduced integration, hourglass control) solid elements [15].

\subsection{Temperature distributions}

Various simplifications of the temperature distributions were used in the finite element models to evaluate the effects of thermal gradients. Table 6 lists the four varieties. The "uniform 1" temperature distribution assumes the entire cross-section is uniformly heated to the average cross-sectional temperature measured at the time of failure. The "uniform 2" temperature distribution assumes that the entire cross-section is uniformly heated to the temperature recorded at the Tw1/2 thermocouple (mid-depth of the web) at the time of failure. Both "gradient 1 " and "gradient 2" temperature distributions use the top and bottom flange temperatures based on an average of the thermocouple readings from Ttf1 and Ttf2 (top flange), and Tbf1 and Tbf2 (bottom flange), respectively (i.e., regions 1 and 5 of Figure 4). The only difference between "gradient 1" and "gradient 2 " is the web temperature; "gradient 1" assumes a uniform web temperature recorded from the Tw1/2 thermocouple at the failure time, while "gradient 2" uses the temperatures recorded from the Tw1/4, Tw1/2, and Tw3/4 thermocouples at the failure time (i.e. regions 2, 3, and 4 of Figure 4).

In the finite element models, a steady-state temperature is applied to the girder section based on one of the four approaches of Table 6, and the applied load is increased until failure. This approach is opposite to the experiments, which held the load constant and increased the temperature until failure. However, since this study seeks to predict the ultimate shear postbuckling load (not the time to failure) based on various modeling parameters, this approach is proper. 


\subsection{Initial imperfection and model validation}

Nonlinear postbuckling analyses were conducted to determine the ultimate postbuckling shear strength, $V_{u}^{F E}$, of the four finite element models shown in Figure 7. These analyses require the insertion of an initial geometric imperfection to perturb the mesh, which allows the loaddisplacement curve to proceed beyond the bifurcation point and reach $V_{u}{ }^{F E}$. To create this initial geometric imperfection, the eigenmode shape associated with the lowest positive eigenvalue is multiplied by a defined scale factor. Previous research found that a scale factor of $D / 10000$ was sufficient [2] and this scale factor was selected for the present study.

For the non-composite models (Figure 7) the nonlinear postbuckling analysis procedure was validated with published experimental data for web shear buckling tests conducted at $20^{\circ} \mathrm{C}$, $400^{\circ} \mathrm{C}, 565^{\circ} \mathrm{C}$, and $700^{\circ} \mathrm{C}[7,19]$. The specimens in these experiments were reproduced using the procedures (mesh, imperfection, elements, etc.) discussed above and good correlation was observed with the high temperature tests. Further discussion of these finite element validation studies may be found in $[2,5]$.

Aziz et al. have shown in [4] that using the same finite element modeling procedures described here can produce finite element results that correlate well with the experimental results for models with composite action. In this paper, we are examining a pure shear condition and therefore only one panel is modeled, not the full beam as in [4]. Therefore, when comparing with the experimental results one must consider this difference as well as the fact that in the composite girder experiments a bending moment was present in addition to shear.

It is important to note that the results of the finite element studies will be used mostly in comparison to one another to evaluate the effects of the various parameters studied. By 
evaluating the differences in results, an evaluation of the sensitivity of the results to a given parameter can be made.

\subsection{Finite Element Results and Discussion}

The results of the finite element studies are shown in Table 7. Also shown in Table 7 is a comparison to the experimental results, where The $V_{u}^{F E}$ represents the finite element solution of the ultimate postbuckling shear strength, and $V_{u}{ }^{E x p}$ represents the experimental value. These results are discussed in detail in the sections that follow.

\subsection{Effect of Composite Slab}

Table 7 shows that the parameter with the greatest sensitivity to the results is the presence, or not, of a composite slab. The composite slab adds a significant amount of strength to the panel, between $29 \%$ and $81 \%$ more than not including the slab. Further, the table shows that even though the finite element model is an approximation of the experiments as discussed previously, the model with a slab is able to capture reasonable estimates of the ultimate postbuckling shear capacity of the girder, most of which are conservative estimates, depending on the temperature distributions assumed.

\subsection{Effect of Flange Boundary Conditions}

When the flange is modeled with simply supported conditions, lower $V_{u}{ }^{F E}$ values are obtained compared to experiments and to other models. The difference is larger in girder G2 than G3, where for gradient $2, V_{u}$ is $29 \%$ and $20 \%$ lower than $V_{u}{ }^{F E}$ with flanges, respectively, when simply supported boundary conditions are used. For the case where uniform temperatures are used, the difference decreases to $19 \%$ and $6 \%$ for Girders G2 and G3, respectively. Studies of 
plate shear buckling at ambient temperature [20] indicate that if the flange to web thickness ratio $\left(t_{f} / t_{w}\right)$ is less than about 5 , simply supported boundary conditions can be used to represent the flange. In this study the flange to web thickness ratio $\left(t_{f} / t_{w}\right)$ equals 2.6 . Thus, the results indicate that in elevated temperature conditions, and in particular conditions with thermal gradients, the results are more sensitive to flange representation than at ambient temperature.

\subsection{Effect of Temperature Gradient}

Uniform 1, which uses an average temperature of the full section, results in the highest $V_{u}$ values in comparison to the other temperature distributions. This is due to the inclusion of the cooler top flange in estimating the temperature, which leads to a higher uniform temperature. Uniform 1 also has the best correlation to the experimental results, but this is due to the lower temperature increasing the strength, thus accounting for the additional strength given by the composite slab.

Uniform 2, gradient 1, and gradient 2 all yield similar results. This is due to the web temperature being essentially the same. Gradient 1 and gradient 2 have slightly larger values than uniform 2 since the cooler flange provides some additional rotational restraint; however, this effect is not significant.

\subsection{Summary and Conclusions}

This paper presented a detailed evaluation of the web shear buckling response of two steel plate girder specimens that were experimentally tested under transient temperature conditions. In addition, finite element studies were developed that studied the sensitivity that three parameters have on the ultimate postbuckling capacity of steel webs in plate girders: (1) boundary conditions 
representing the flange, (2) representation of thermal gradients, and (3) composite action with the slab.

The list below summarizes the important experimental observations related to web shear buckling. Since only two specimens were tested, more experiments are needed for further validation:

- Experiments show that given the same girder depth $(D)$, the larger the distance between transverse stiffeners $(a)$, the longer the time lapse between elastic shear buckling and ultimate shear buckling.

- Elastic shear buckling was reached at a higher temperature for girder G2 (with $a / D=1.0$ ) compared to girder $\mathrm{G} 3$ (with $a / D=1.5$ ). This is due to larger $a / D$ ratios resulting in lower buckling coefficients $(k)$ and thus lower critical buckling loads.

- Ultimate shear buckling was reached at approximately the same temperature for girders G2 and G3. Since both girders have the same load ratio (i.e., applied load to design capacity load based on ultimate shear buckling capacity), the same reduction in mechanical material properties is needed (which is a function of temperature) to achieve the load capacity.

The finite element studies, which evaluated the sensitivity of several modeling parameters on the ultimate postbuckling capacity of steel webs in plate girders, led to the following conclusions:

- The composite slab adds significant shear capacity to the section. Neglecting the slab results in predictions that are about half that observed in the experiments.

- Assuming simply supported boundary conditions for the flange can lead to estimates of postbuckling shear strength that is between $19 \%$ and $29 \%$ lower than models that explicitly model the flange. This difference in range is dependent on the thermal gradient temperature 
distributions, where models with thermal gradients have larger sensitivities to the method of modeling the flange.

- The cooler top flange provides some additional strength for postbuckling shear capacity, but it is not significant.

- Modeling the girder with a uniform temperature equal to the temperature of the web leads to similar results as modeling with thermal gradients.

- The most effective and efficient model for predicting the ultimate shear buckling capacity of composite steel plate girders is to use a constant temperature through the section equal to the average temperature of the entire cross-section at ultimate shear buckling strength and include the slab.

\section{Acknowledgments}

The authors would like to acknowledge Mr. Siavosh Ravanbakhsh, the manager of the Civil Infrastructure Laboratory at Michigan State University, for his help with the experimental tests, as well as Ph.D. students Ankit Agrawal and Anuj Shakya. This research was made with Government support under and awarded by DoD, Air Force Office of Scientific Research, National Defense Science and Engineering Graduate (NDSEG) Fellowship, 32 CFR 168a, provided to Dr. Glassman. Support from the University of Sulaimani in the form of a scholarship was provided to Dr. Aziz. This research was also sponsored by the National Science Foundation (NSF) under grant CMMI-1068252. All opinions, findings, and conclusions expressed in this paper are of the authors and do not necessarily reflect the policies and views of the sponsors.

\section{References}


[1] M. Garlock, I. Payá-Zaforteza, V. Kodur and L. Gu, "Fire Hazard in Bridges: Review, Assessment and Repair Strategies," Engineering Structures, vol. 35, pp. 89-98, 2012.

[2] M. E. M. Garlock and J. D. Glassman, "Elevated temperature evaluation of an existing analytical model for steel web shear buckling," Journal of Constructional Steel Research, vol. 101, pp. 395-406, 2014.

[3] D. C. Schiffner, "Analysis of Collapsed Alabama Bridge due to Fire," (Princeton University M.S. Thesis), 2011.

[4] E. M. Aziz, V. K. Kodur, J. D. Glassman and M. E. M. Garlock, "Behavior of steel bridge girders under fire conditions," Journal of Constructional Steel Research, vol. 106, pp. 11-22, 2015.

[5] J. D. Glassman and M. Garlock, "Post-fire Strength Assessment of Steel Bridges Based on Residual Out-ofPlane Web Deformations," in Structures Congress, Boston, 2014.

[6] V. Vimonsatit, K.-H. Tan and S.-K. Ting, "Shear strength of plate girder web panel at elevated temperature," Journal of Constructional Steel Research, vol. 63, pp. 1442-1451, 2007.

[7] V. Vimonsatit, K.-H. Tan and Z.-H. Qian, "Testing of Plate Girder Web Panel Loaded in Shear at Elevated Temperature," Journal of Structural Engineering, vol. 133, no. 6, pp. 815-824, 2007.

[8] J. Alos-Moya, I. Paya-Zaforteza, M. Garlock, E. Loma-Ossorio, D. Schiffner and A. Hospitaler, "Analysis of a bridge failure due to fire using computational fluid dynamics and finite element models," Engineering Structures, vol. 68, pp. 96-110, 2014.

[9] G. Peris-Sayol, I. Paya-Zaforteza, J. Alos-Moya and A. Hospitaler, "Analysis of the influence of structural models in fire responses of steel girder bridges," in Structures Congress, Portland, 2015.

[10] G. Peris-Sayol, I. Paya-Zaforteza, J. Alos-Moya and A. Hospitaler, "Analysis of the influence of geometric, modeling and environmental parameters on the fire response of steel bridges subjected to realisitc fire scenarios," Computers \& Structures, vol. 158, pp. 333-345, 2015.

[11] E. M. Aziz, "Response of Fire Exposed Steel Bridge Girders," Thesis submitted to Civil and Environmental Engineering Department at Michigan State University, East Lansing, USA, 2015.

[12] American Association of State Highway and Transportation Officials, "AASHTO LRFD Bridge Design Specifications (6th Edition)," 2012. [Online]. Available: http://www.knovel.com/knovel2/Toc.jsp?BookID=4852. [Accessed 13 February 2013].

[13] European Committee for Standardization (CEN), "Eurocode 3: Design of steel structures," CEN, Brussels, 2002.

[14] S. C. Lee and C. H. Yoo, "Strength of Plate Girder Web Panels Under Pure Shear," Journal of Structural Engineering, vol. 124, no. 2, pp. 184-194, 1998.

[15] Dassault Systemes, "Abaqus 6.11ef Online Documentation," 15 March 2015. [Online]. Available: http://cee.princeton.edu:2080/v6.11/.

[16] S. P. Timoshenko and J. M. Gere, Theory of Elastic Stability, Second Edition, New York: McGraw-Hill Book Company, Inc., 1961.

[17] R. D. Ziemian, Guide to Stability Design Criteria for Metal Structures, 6th ed., Hoboken: John Wiley \& Sons, 2010.

[18] S. Lee, J. Davidson and C. Yoo, "Shear Buckling Coefficients of Plate Girder Web Panels," Computers and Structures, vol. 59, no. 5, pp. 789-795, 1996.

[19] A. S. Elamary, "Ultimate Shear Resistance of Plate Girders Part 2 - Hoglund Theory," International Journal of Civil, Architectural, Structural and Construction Engineering, vol. 7, no. 12, pp. 580-588, 2013.

[20] J. D. Glassman and M. E. M. Garlock, "A Compression Model for Ultimate Postbuckling Shear Strength," submitted to Thin-Walled Structures.

[21] [Online]. Available: http://extras.mnginteractive.com/live/media/site515/2013/0509/20130509_014114_Tanker\%20Fire_Hake_500 .jpg. [Accessed 17 March 2015]. 


\section{List of figures.}
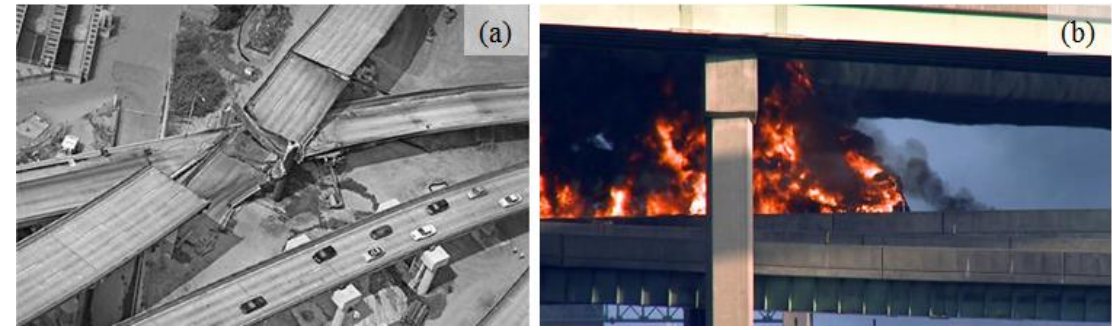

(b)

Figure 1. (a) MacArthur Maze fire in Oakland, CA [1], (b) I-81/Rt 322 interchange fire in Harrisburg, PA [21], and (c) Malfunction Junction fire in Birmingham, AL (photo courtesy of Alabama Department of Transportation).

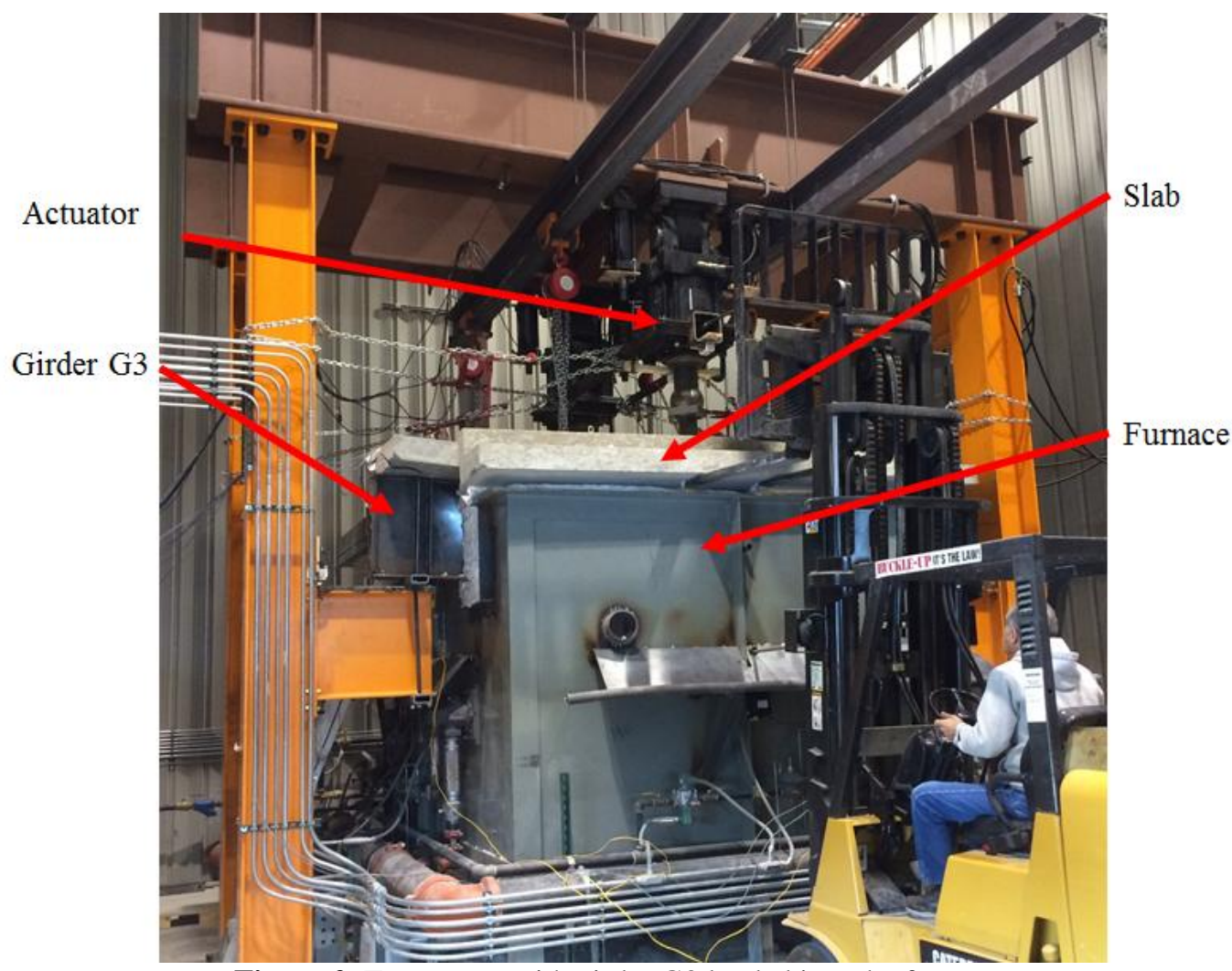

Figure 2. Test set-up with girder G3 loaded into the furnace. 

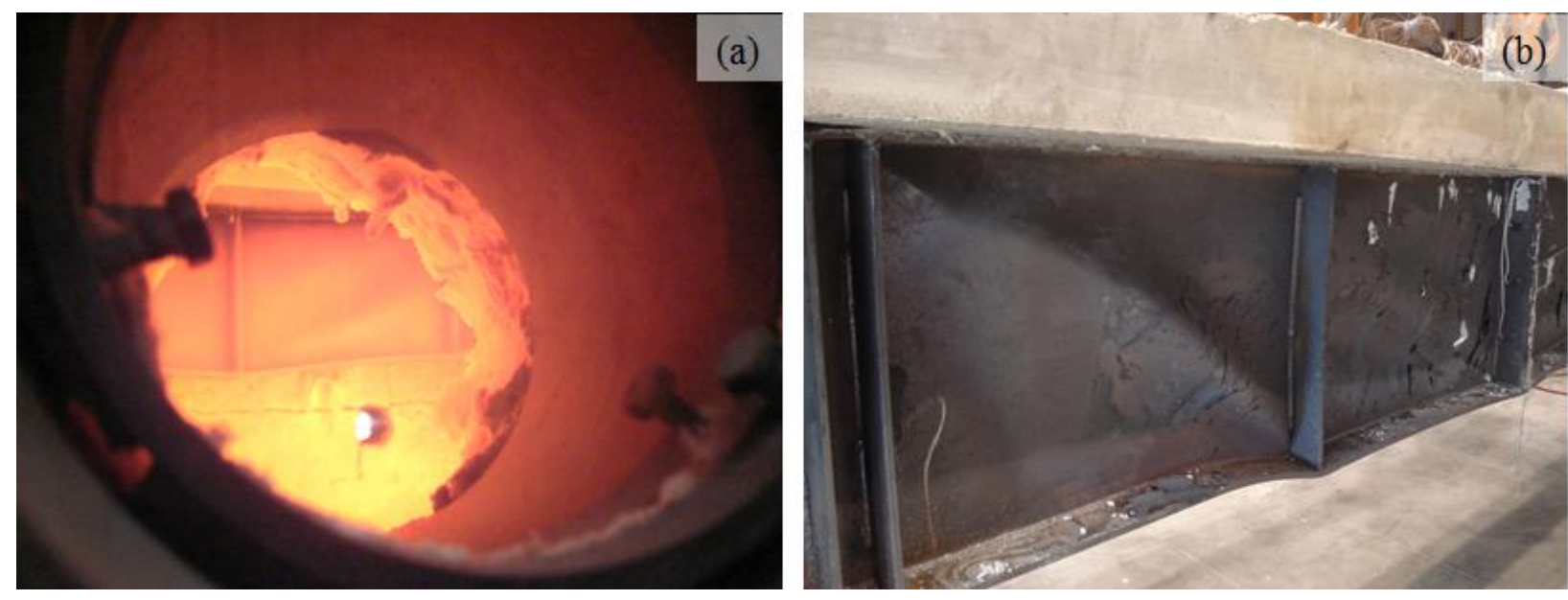

Figure 3. Web shear buckling observed in girder G3 (a) during the fire test, and (b) post-test at ambient temperature (image reproduced from $[4,11]$.

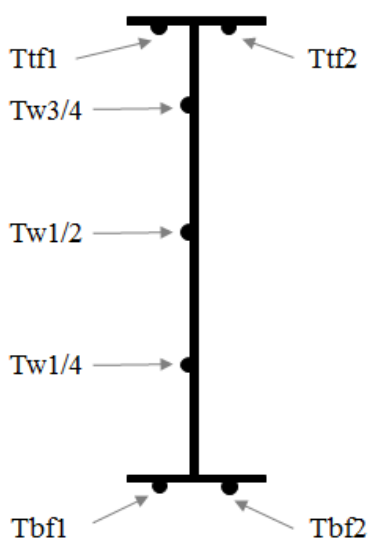

(a)

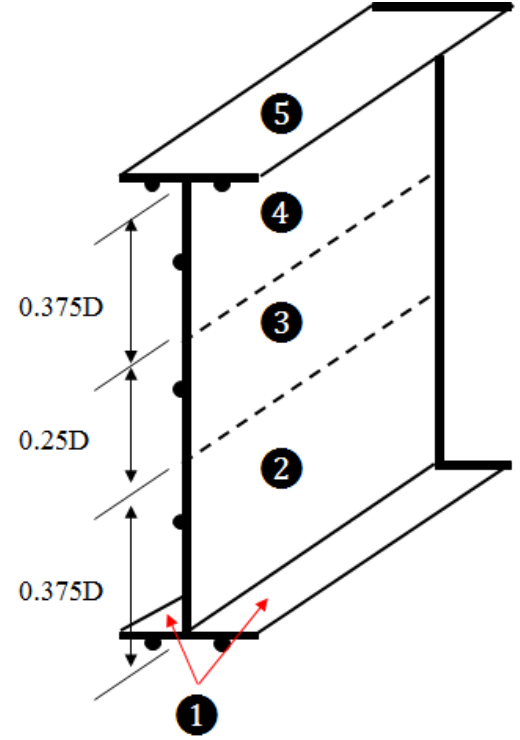

(b)

Figure 4. (a) Cross-sectional view of girders G2 and G3 (without the concrete slab) with thermocouple locations labeled corresponding to Figure 5, and (b) regions 1, 2, 3, 4, and 5 using thermocouple data recorded from (1) the average of Tbf1 and Tbf2, (2) Tw1/4, (3) Tw1/2, (4) Tw3/4, and (5) the average of Ttf1 and Ttf2, respectively. 

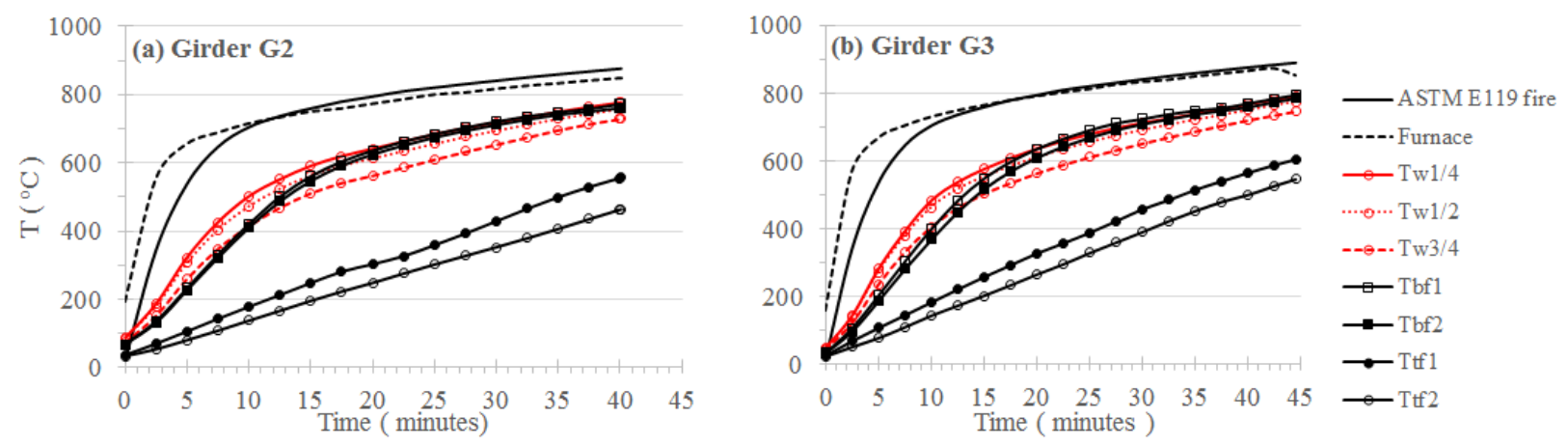

Figure 5. Thermocouple temperatures through the steel section of (a) girder G2 and (b) girder G3.

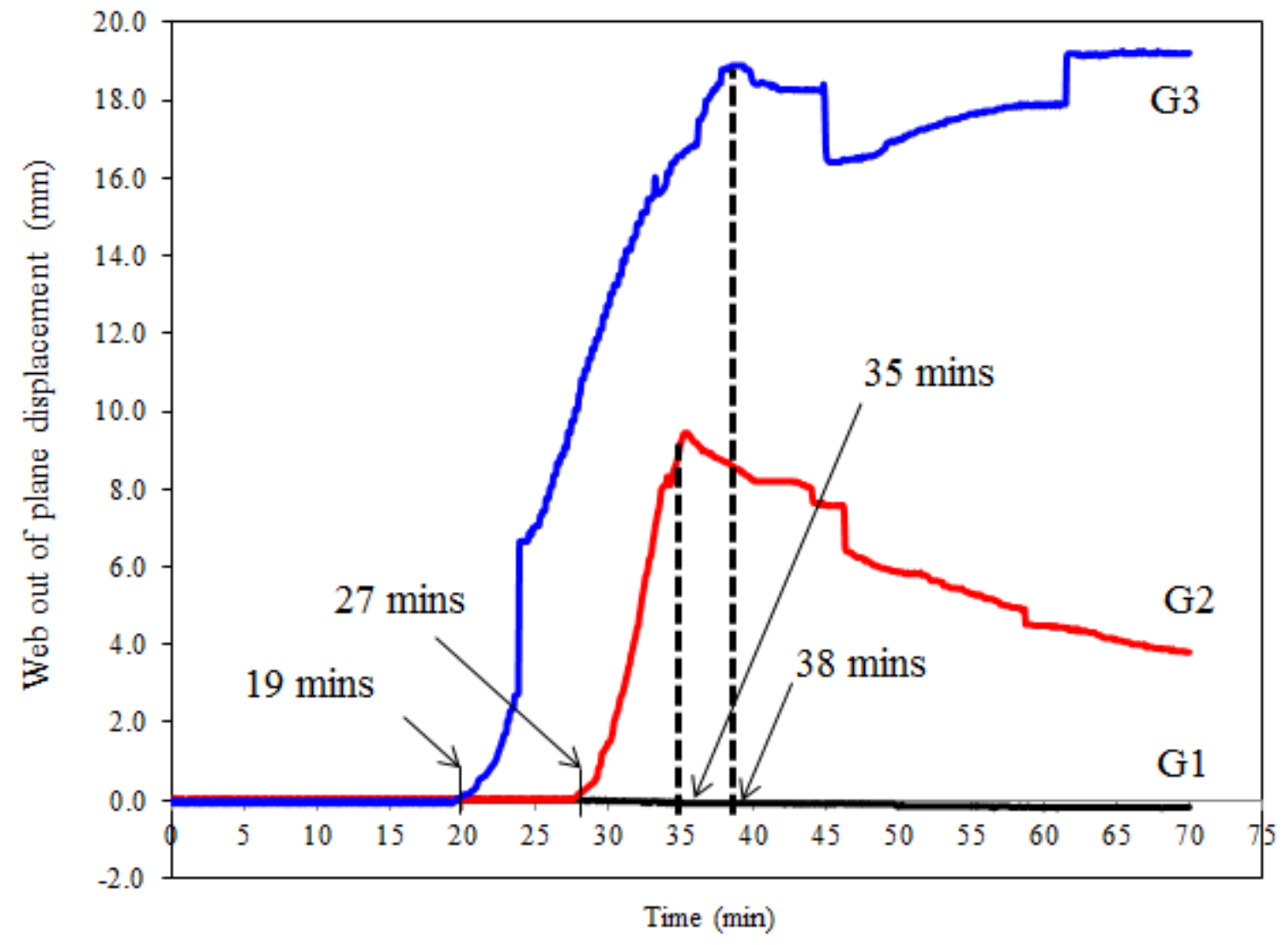

Figure 6. Out-of-plane displacement measured at approximately the center of the web panel based on the test setup shown in $[4,11]$. 


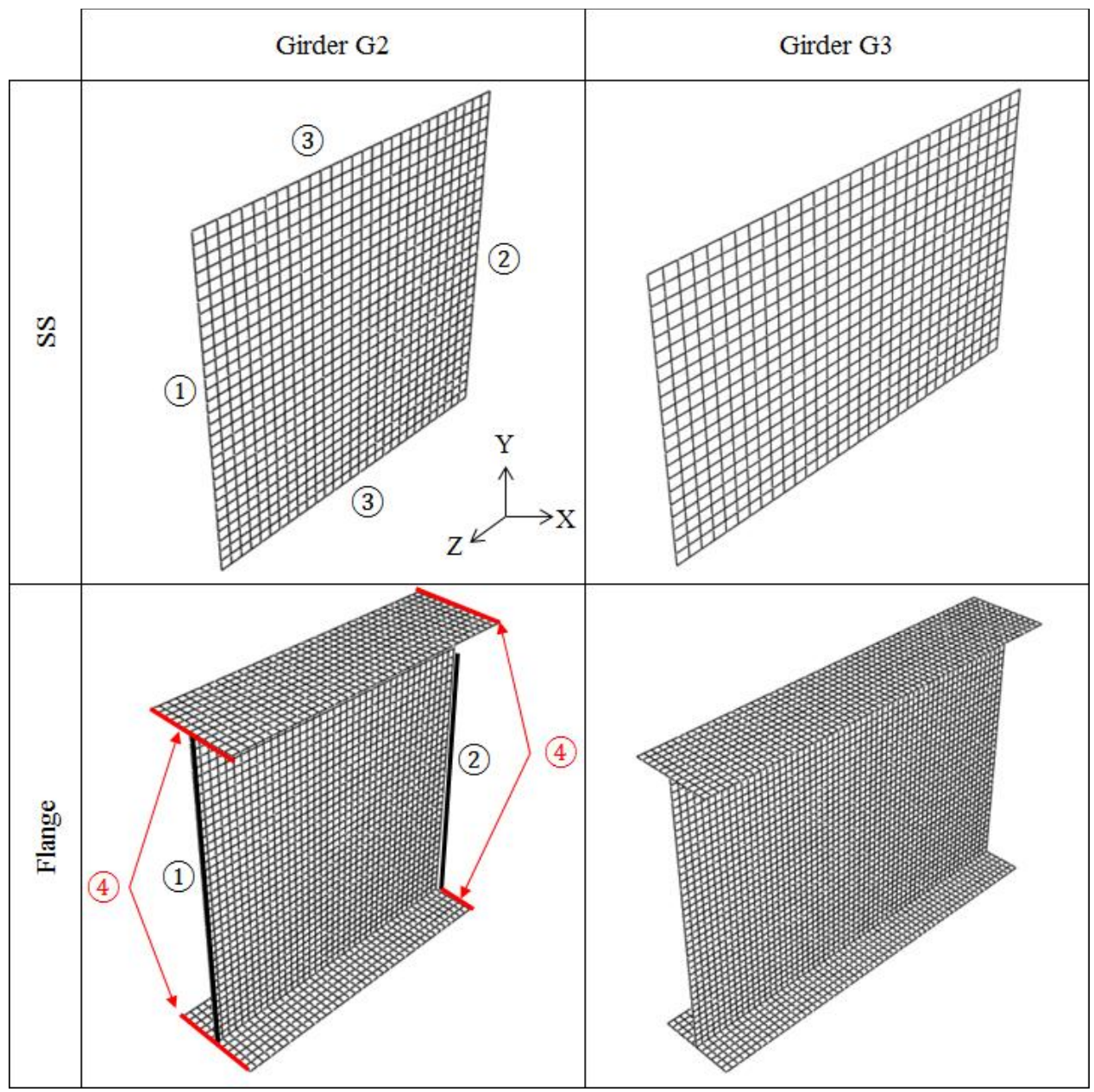

Figure 7. SS and Flange finite element models for girders G2 and G3.

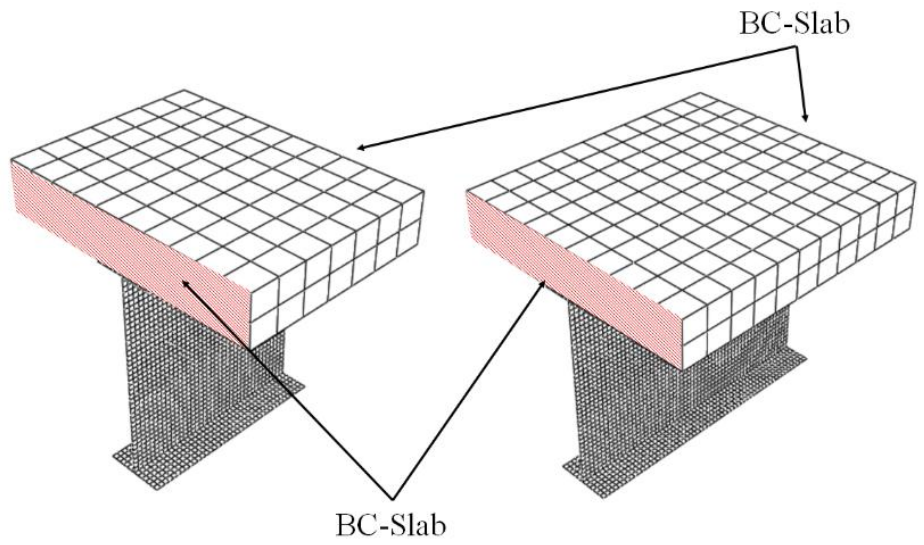

(a) (b)

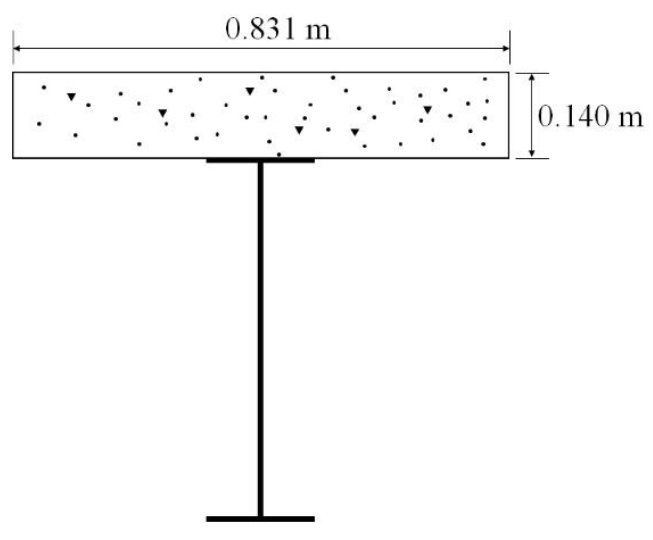

(c)

Figure 8. Finite element models with concrete slabs for girders (a) G2 and (b) G3; (c) cross-sectional view with dimensions of the concrete slab labeled. 


\section{List of tables.}

Table 1. Physical dimensions and loading parameters for girders G2 and G3.

\begin{tabular}{|c|c|c|c|}
\hline & Girder G2 & Girder G3 & Description \\
\hline $\mathrm{a}(\mathrm{mm})$ & 587.4 & 881.1 & distance between trans verse stiffeners \\
\hline $\mathrm{D}(\mathrm{mm})$ & 587.4 & 587.4 & clear depth of web plate between flanges \\
\hline $\mathrm{t}_{\mathrm{w}}(\mathrm{mm})$ & 4.8 & 4.8 & web thickness \\
\hline $\mathrm{L}(\mathrm{mm})$ & 3658 & 3658 & span between supports \\
\hline $\mathrm{a} / \mathrm{D}$ & 1.00 & 1.5 & web panel aspect ratio \\
\hline $\mathrm{D} / \mathrm{t}_{\mathrm{w}}$ & 122 & 122 & web slenderness ratio \\
\hline $\mathrm{b}_{\mathrm{f}}(\mathrm{mm})$ & 177.8 & 177.8 & flange width \\
\hline $\mathrm{t}_{\mathrm{f}}(\mathrm{mm})$ & 12.7 & 12.7 & flange thickness \\
\hline $\mathrm{V}_{\mathrm{cr}}(\mathrm{kN})$ & 336 & 239 & elastic shear buckling strength ${ }^{a}$ \\
\hline $\mathrm{V}_{\mathrm{u}}^{\text {Design }}(\mathrm{kN})$ & 480 & 399 & ultimate shear buckling strength ${ }^{a}$ \\
\hline $\mathrm{V}^{\operatorname{Exp}}(\mathrm{kN})$ & 538 & 448 & applied load \\
\hline $\mathrm{V}^{\mathrm{Exp}} / \mathrm{V}_{\mathrm{u}}^{\text {Design }}$ & 0.56 & 0.56 & \\
\hline Failure limit state & flexural $^{\mathrm{b}}+$ shear $^{\mathrm{c}}$ & shear ${ }^{c}$ & \\
\hline
\end{tabular}

Notes: ${ }^{a}$ Calculated from 2012 AASHTO LRFD Bridge Design Specifications [12].

${ }^{b, c}$ Flexural and shear failures imply failure due to yielding and web shear buckling, respectively.

Table 2. Temperatures measured through the cross-sections of girders G2 and G3 at elastic and ultimate shear buckling (labeled "elastic buckling" and "ultimate capacity," respectively). All values in ${ }^{\circ} \mathrm{C}$.

\begin{tabular}{|c|c|c|c|c|c|c|}
\cline { 2 - 7 } & \multicolumn{3}{|c|}{ Girder G2 } & \multicolumn{3}{c|}{ Girder G3 } \\
\hline & $\begin{array}{c}\text { Elastic } \\
\text { buckling }\end{array}$ & $\begin{array}{c}\text { Ultimate } \\
\text { capacity }\end{array}$ & $\Delta \mathrm{T}$ & $\begin{array}{c}\text { Elastic } \\
\text { buckling }\end{array}$ & $\begin{array}{c}\text { Ultimate } \\
\text { capacity }\end{array}$ & $\Delta \mathrm{T}$ \\
\hline Top flange & 354 & 453 & 99 & 283 & 514 & 231 \\
\hline Tw3/4 & 629 & 697 & 68 & 552 & 707 & 155 \\
\hline Tw1/2 & 673 & 731 & 58 & 600 & 738 & 138 \\
\hline Tw1/4 & 698 & 749 & 51 & 625 & 756 & 131 \\
\hline Bottom flange & 695 & 744 & 49 & 607 & 754 & 147 \\
\hline
\end{tabular}

Table 3. Material properties for girders G2 and G3 based on steel coupon tests.

\begin{tabular}{|c|cc|c|c|c|}
\hline Coupon & $\begin{array}{c}\boldsymbol{\sigma}_{\mathbf{y}, \mathbf{0 . 2}} \\
(\mathbf{M p a})\end{array}$ & $\begin{array}{c}\boldsymbol{\sigma}_{\mathbf{u}} \\
(\mathbf{M p a})\end{array}$ & $\boldsymbol{\varepsilon}_{\mathbf{u}}$ & $\boldsymbol{\varepsilon}_{\text {rupture }}$ & $\begin{array}{c}\mathbf{E} \\
(\mathbf{M p a})\end{array}$ \\
\hline 1 & 436.5 & 498 & 0.0589 & 0.0893 & 218250 \\
2 & 503.1 & 570 & 0.0544 & 0.0759 & 251550 \\
\hline 3 & 501.4 & 566 & 0.0563 & 0.0814 & 250700 \\
\hline Average & 480.3 & 545 & 0.0565 & 0.0822 & 240167 \\
\hline
\end{tabular}


Table 4. Boundary conditions referring to sides (1), (2), (3), and (4) in Figure 7.

\begin{tabular}{|c|c|c|c|c|c|c|}
\hline \multirow{2}{*}{$(1)$} & \multicolumn{3}{|c|}{ Translation } & \multicolumn{3}{|c|}{ Rotation } \\
\hline (2) & $\mathbf{U}_{\mathbf{X}}$ & $\mathbf{U}_{\mathbf{Y}}$ & $\mathbf{U}_{\mathbf{Z}}$ & $\mathbf{U R}_{\mathbf{X}}$ & $\mathbf{U R}_{\mathbf{Y}}$ & $\mathbf{U R}_{\mathbf{Z}}$ \\
\hline (3) & $\mathrm{x}$ & $\mathrm{x}$ & $\mathrm{x}$ & $\mathrm{x}$ & & $\mathrm{x}$ \\
\hline (4) & $\mathrm{x}$ & & $\mathrm{x}$ & $\mathrm{x}$ & & $\mathrm{x}$ \\
\hline & $\mathrm{x}$ & & $\mathrm{x}$ & $\mathrm{x}$ & $\mathrm{x}$ & \\
\hline & $\mathrm{x}$ & & $\mathrm{x}$ & & $\mathrm{x}$ & $\mathrm{x}$ \\
\hline
\end{tabular}

Table 5. Material properties for the concrete slab [4].

\begin{tabular}{c|c|c|c|}
\hline $\begin{array}{c}\text { Age } \\
(\text { days })\end{array}$ & $\begin{array}{c}\mathbf{f}_{\mathbf{c}} \\
(\mathbf{M P a})^{\mathbf{a}}\end{array}$ & $\begin{array}{c}\mathbf{f}_{\mathbf{t}} \\
(\mathbf{M P a})^{\mathbf{b}}\end{array}$ & $\begin{array}{c}\mathbf{f}_{\mathbf{c r}} \\
(\mathbf{M P a})^{\mathbf{c}}\end{array}$ \\
\hline 14 & 436.5 & 498 & 0.0589 \\
\hline 28 & 503.1 & 570 & 0.0544 \\
\hline $210^{\mathrm{d}}$ & 501.4 & 566 & 0.0563 \\
\hline
\end{tabular}

Table 6. Temperature distributions assumed for various finite element models (in Celsius).

\begin{tabular}{|c|c|c|c|c|c|c|}
\hline \multirow[b]{2}{*}{ Girder } & \multirow{2}{*}{$\begin{array}{l}\text { Temperature } \\
\text { distribution }\end{array}$} & \multicolumn{5}{|c|}{ Temperature $\left({ }^{\circ} \mathrm{C}\right)$} \\
\hline & & $\begin{array}{l}\text { Bottom } \\
\text { flange }\end{array}$ & $\begin{array}{c}\text { Top } \\
\text { flange }\end{array}$ & $\begin{array}{c}\text { Web } \\
\text { (Tw1/4) }\end{array}$ & $\begin{array}{c}\text { Web } \\
\text { (Tw1/2) }\end{array}$ & $\begin{array}{c}\text { Web } \\
(\text { Tw3/4) }\end{array}$ \\
\hline \multirow{4}{*}{$\mathrm{G} 2$} & uniform 1 & 675 & 675 & 675 & 675 & 675 \\
\hline & uniform 2 & 731 & 731 & 731 & 731 & 731 \\
\hline & gradient 1 & 744 & 453 & 731 & 731 & 731 \\
\hline & gradient 2 & 744 & 453 & 749 & 731 & 697 \\
\hline \multirow{4}{*}{ G3 } & uniform 1 & 694 & 694 & 694 & 694 & 694 \\
\hline & uniform 2 & 738 & 738 & 738 & 738 & 738 \\
\hline & gradient 1 & 754 & 514 & 738 & 738 & 738 \\
\hline & gradient 2 & 754 & 514 & 756 & 738 & 707 \\
\hline
\end{tabular}


Table 7. Results of finite element analyses.

\begin{tabular}{|c|c|c|c|c|c|c|c|}
\hline Model \# & Girder & Slab & $\begin{array}{l}\text { Flange } \\
\text { Boundary } \\
\text { Condition }\end{array}$ & $\begin{array}{l}\text { Temperature } \\
\text { distribution }\end{array}$ & $\begin{array}{l}\mathbf{V}_{\mathbf{u}}^{\text {Exp }} \\
(\mathbf{k N})\end{array}$ & $\begin{array}{c}\mathbf{V}_{\mathbf{u}}^{\mathbf{F E}} \\
(\mathbf{k N})\end{array}$ & $\mathbf{V}_{\mathbf{u}}^{\mathbf{F E}} / \mathbf{V}_{\mathbf{u}}^{\mathbf{E}}$ \\
\hline 1 & \multirow{11}{*}{ G2 } & No slab & \multirow{4}{*}{ Flange } & uniform 1 & 269 & 191 & 0.71 \\
\hline 2 & & No slab & & uniform 2 & 269 & 150 & 0.56 \\
\hline 3 & & No slab & & gradient 1 & 269 & 146 & 0.54 \\
\hline 4 & & No slab & & gradient 2 & 269 & 149 & 0.55 \\
\hline 5 & & No slab & \multirow{3}{*}{ SS } & uniform 1 & 269 & 155 & 0.58 \\
\hline 6 & & No slab & & uniform 2 & 269 & 123 & 0.46 \\
\hline 7 & & No slab & & gradient 2 & 269 & 106 & 0.39 \\
\hline 8 & & Slab & \multirow{4}{*}{ Flange } & uniform 1 & 269 & 280 & 1.04 \\
\hline 9 & & Slab & & uniform 2 & 269 & 194 & 0.72 \\
\hline 10 & & Slab & & gradient 1 & 269 & 198 & 0.74 \\
\hline 11 & & Slab & & gradient 2 & 269 & 202 & 0.75 \\
\hline 12 & \multirow{11}{*}{ G3 } & No slab & \multirow{4}{*}{ Flange } & uniform 1 & 224 & 124 & 0.55 \\
\hline 13 & & No slab & & uniform 2 & 224 & 94 & 0.42 \\
\hline 14 & & No slab & & gradient 1 & 224 & 115 & 0.51 \\
\hline 15 & & No slab & & gradient 2 & 224 & 113 & 0.50 \\
\hline 16 & & No slab & \multirow{3}{*}{ SS } & uniform 1 & 224 & 116 & 0.52 \\
\hline 17 & & No slab & & uniform 2 & 224 & 88 & 0.39 \\
\hline 18 & & No slab & & gradient 2 & 224 & 90 & 0.40 \\
\hline 19 & & Slab & \multirow{4}{*}{ Flange } & uniform 1 & 224 & 211 & 0.94 \\
\hline 20 & & Slab & & uniform 2 & 224 & 170 & 0.76 \\
\hline 21 & & Slab & & gradient 1 & 224 & 176 & 0.79 \\
\hline 22 & & Slab & & gradient 2 & 224 & 175 & 0.78 \\
\hline
\end{tabular}

